\title{
Creating Scalable Location-Based Games: Lessons from Geocaching
}

\author{
Carman Neustaedter \\ Simon Fraser University, School of Interactive Arts and Technology \\ carman_neustaedter@sfu.ca
}

Anthony Tang

University of Calgary

tonyt@ucalgary.ca

Tejinder K. Judge

Virginia Tech

tkjudge@vt.edu

\begin{abstract}
Location-based games seek to move computer gaming out from behind the PC and into the "real world" of cities, streets, parks, and other locations. This real world physicality makes the experience fun for game players, yet it brings the unique challenge of creating and orchestrating such a game. That is, location-based games are often difficult to create, grow, and maintain over long periods of time. Our research investigates how location-based games can be designed to overcome this challenge of scalability. We studied the well-established location-based game of Geocaching through active participation and an online survey to better understand how it has succeeded in maintaining user involvement and growth over the last decade. Findings show that Geocaching benefits by having players directly create game content, including both lightweight and elaborate creations. Geocaching has also made it simple for players to perform game orchestration by monitoring game content, other players, and even non-players. We then characterize location-based games according to various attributes and suggest how the lessons learned from Geocaching could be applied more generally to the design of other location-based games and in which cases they should not be applied.
\end{abstract}

\section{Author Keywords}

Geocaching, pervasive games, location-based games, community, Global Positioning System $(G P S)$ 


\section{Introduction}

Location-based games are played in everyday places, where game information is tied to these locations [20]. Over the last decade, researchers, artists, and companies have created and studied a variety of location-based games to investigate cultural, societal, technological, and community issues. For example, in the game Uncle Roy All Around You (Uncle Roy), players are directed through the streets of an urban center based on ambiguous clues given to them on a PDA by a stranger [7]. The goal is to find the mysterious character known as Uncle Roy. In this case, the game explores the culture of trust, as players must decide whether or not to trust directions given by people who are completely unknown to them. .

One challenge that exists with many location-based games is the creation and orchestration of game content and activities [9]. By creation, we mean the construction and placement of game content. By orchestration, we are referring to the monitoring of players' activities in the game, and the quality and continued availability of game content, to ensure that play proceeds smoothly for players. For example, in Uncle Roy All Around You [7], creation includes planning the scripts and routes that game administrators will use to lead players. Orchestration involves actively monitoring players to ensure they stay out of harm's way and continue to participate in the game. Here the orchestration needs are highly dynamic [9]. In contrast to a typical board game, orchestration is far more complex: the physical constraints of the game appear unbounded to the player, as do the rules (i.e., who to interact with).

In general, game creation and orchestration in location-based games is crucial to a game's success. If it is done poorly, players may not enjoy the game or may be at risk; perhaps, even worse, non-players who do not realize they are part of a game as bystanders may be at risk [9]. For example, in Uncle Roy, if orchestration was done poorly, players could accidentally trespass into incorrect buildings, which may cause unnecessary and potentially dangerous altercations with non-players. Similarly, Geocaching has gained notoriety amongst police officials as poorly-placed geocaches have resulted in bomb scares (search online for "geocache bomb scare"). In this case, the risk is more of a perception than a real one, but, nonetheless, the construction and placement of content can have dramatic effects. Pragmatically, challenges with creation and orchestration also mean that location-based games are often "one offs" and only available in a single location or conducted over a short period of time, never to be run again. As a result, participation is limited or game players cannot continue to play like they might computer or online games.

Our interest is in understanding how location-based games can be designed to be scalable. By scalable, we are referring to a game's ability to be: 1) played and orchestrated over long periods of time in a variety of locations, and 2) played by a large number of players (e.g., hundreds or thousands of people). In some cases, location-based games are meant to be performance art and, as such, this type of scalability may not necessarily be desired. Instead, the game may have other goals such as providing different cultural perspectives. However, in other situations, it may be advantageous to be able to have a game that can be played in various locations over a long 
period of time. To understand this, we turn to what is arguably the most successful location-based game to date based on its longevity, user participation, and global presence: Geocaching. The game of Geocaching has been in existence since the year 2000 and currently has over four million players worldwide [12]. In simplest terms, Geocaching is a GPS-enabled treasure hunt. Players known as geocachers, or cachers for short, hide physical containers with a paper logbook and record the GPS coordinates of the container's location on the Geocaching website. Other geocachers then use this information to find the containers.

We first studied Geocaching with a combination of in-depth participation over a one-year period and an online survey of 185 geocachers [22]. Our findings highlighted the ways that geocachers actively create location-based experiences for other geocachers. We also showed how maintenance of the activity is also mostly left in the hands of the players. Our results from this are presented in [22]. Yet two years later, we recognized that our earlier work was limited in that it was more descriptive in nature than prescriptive. This made it difficult to understand in what context the lessons from Geocaching should or could be applied. The work was also tied more directly to location-based experiences in general, as opposed to location-based games, our current focus of research. This made it difficult to understand its direct applicability to location-based game design. As such, we have extended our study of Geocaching to include an additional year of active participation, which comes with a needed reflection on the results of our earlier work. The current article explores the findings from our earlier Geocaching studies by situating them within the context of location-based games. Then, through critical reflection, we suggest how game designers and researchers might apply the lessons from Geocaching to other types of locationbased games.

Our article first describes related work on designing scalable location-based games. Second, we outline our study methodology including two years of active participation and observations of Geocaching along with an online survey. Third, we describe our findings on game creation and orchestration. Fourth, in our discussion section, we categorize existing location-based games, and, through this, suggest how lessons from Geocaching could be applied more broadly to locationbased game design.

\section{Related Work}

There exists a plethora of books that describe how to design computer games (e.g., [1,28,29]) Typical topics include structuring games for target audiences, structuring play, storytelling, narrative, and game genres [1,28,29]. One could certainly pull such concepts together to understand how to design a game such that it is both scalable to large volumes of players. Yet none of these topics are explored in the context of games that move away from the traditional desktop computer and they certainly do not broach the genre of location-based games. Thus, applying the concepts to location-based game design is questionable. McGonigal explores the design of "augmented-reality games," of which she includes location-based games, and argues that they should scale to large volumes of players [21]. However, rather than illustrate mechanisms to 
do so, her focus is instead on illustrating why large scale games are important and how they might be able to solve real world social problems (e.g., famine, war) [21].

Recently we have seen the popularity of casual games rise dramatically amongst smartphone (e.g., Apple iPhone, Android, Windows phone) and social media users (e.g., Facebook enthusiasts). Casual games are those that can be easily understood and played in short time increments throughout the day (e.g., Facebook games). Some are even location-based. For example, in Foursquare, players "check-in" in to locations, score points, and can compete with their friends [18]. Such casual games have shown they can successfully scale to large numbers of players. However, the richness of the experiences they offer appears to be less than other noncasual location-based games (e.g., Uncle Roy All Around You, Geocaching). For example, studies of Fourquare have shown that while some players are motivated to use Foursquare because of its game-like properties, game play is not entirely compelling and some simply play in order to have "something to do" when bored [18]. Game elements (e.g., badges) also become less of a motivation for playing over time [18].

There are also academic papers that have specifically looked at the problem of designing scalable location-based games. First, Barkhuus et al. [2] designed a game called Treasure so that it could be played multiple times in order to understand the effects of repeated game play on players' strategies and tactics. Here their strategy was to use both GPS and Wifi within the game in order to determine a players' location. They suggest that to scale such games to even larger number of players, game designers should incorporate the use of mobile ad-hoc networks in addition to GPS and Wifi positioning systems. Second, after analyzing several location-based games (Savannah [8], Uncle Roy [7], Can You See Me Now? [6]), Capra et al. [9] suggest games can scale to large numbers of users through "campaign strategies" where players upload multimedia from their own personal devices in conjunction with events organized by local organizations. Here we see the beginning of the idea that players may directly contribute to game content. Third, Stanley et al. [31] suggest a similar player-focused strategy of game content creation. In their game, PiNiZoRo, parents can create walking routes for the game that their children must follow when playing [31].

We also see other suggestions for creating scalable location-based games that emerge from studies of Geocaching. These are more directly related to our own research. First, forestry studies have described the environmental effects of Geocaching on forests and parks where players need to be concerned that they are not causing environmental destruction when they play [10]. This suggests that scalable location-based games should be designed cautiously to understand what effects a large volume of players might have on play areas. Second, studies have described the key motivations that people have for participating in Geocaching [11,23]. These include giving purpose to walks and/or exercise, personal achievement, and exploring new and unfamiliar places, thereby reconnecting one to their own community or providing them with opportunities to understand new communities [11,23]. This diversity suggests that scalable location-based games should allow players to choose their own personal goals as part of gameplay; this is similar to findings about users' motivations for using Foursquare [18]. Third, we also know that trust becomes an issue when games scale and must be taken into account. Kelley's extensive autobiographical accounts of Geocaching describe how players must trust that an item is in fact 
placed at a certain location, albeit by a stranger, and travel to unknown locations to search [15]. Kelley [15] labels this as thin trust; that is, trust between anonymous people rather than close friends or family [25].

Despite the variety of suggestions offered by the related work, we see little in terms of understanding how player participation in game creation and orchestration can play a role in creating a scalable location-based game. O'Hara [23] and Salovaara et al. [30] highlight this as an important aspect of Geocaching, but do not elaborate on the mechanisms that enable player creation to occur. In the next sections, we build on this related research to explore Geocaching in order to articulate the variety of ways it encourages scalability through content creation and orchestration by players themselves.

\section{Studies of Geocaching}

We studied Geocaching using two main methods: extensive firsthand experiences and an online survey. This took place in several stages over two years.

1. Initial Participation. We initially participated in Geocaching for a period of ten months. This involved the first author finding 250 geocaches and hiding 10, the second author finding 75 geocaches and hiding 1 , and the third author finding 15 and hiding 1 . This provided us with firsthand accounts of the game from the perspective of beginner, intermediate, and advanced cachers and provided many opportunities for interacting with other geocachers through the Geocaching web page logs and messaging system.

2. Online Survey. Four months into our participation, we created and deployed a survey online that included questions targeted at understanding geocache creation and maintenance. For example, sample questions included: "Describe your favorite geocache creation", "What activities did you engage in to plan the hide?", and "How do you know when your geocache needs maintenance?" We recruited respondents via snowball sampling where we posted a link to the survey on the popular micro-blog site, Twitter. We also recruited respondents by posting messages about the survey on eight regional online Geocaching forums throughout the USA and Canada. We received a total of 185 completed surveys. Respondents ranged in Geocaching experience from newcomers to very experienced cachers with thousands of geocache finds. Additional details about respondents can be found in [22].

We analyzed our results from both of the above methods in the context of location-based experiences in general. This involved looking at Geocaching in relation to a broad set of services tied to locations (e.g., delivery of messages based on location [16,17], location-based collecting [24]). Following this, we wanted to reflect on our findings and understand them in the more specific context of location-based games. For this reason, we completed a third research stage. 
3. Extended Participation. The first author extended his Geocaching participation by finding an additional 200 geocaches and hiding 10 over the course of one year (for a total participation of 450 geocache finds and 20 hides). Hunting activities included finding over 80 geocaches in each of two unique areas: Greater Rochester, NY, USA (containing a large number of urban-based geocaches with low finding difficulty), and Greater Vancouver, BC, Canada (containing a large number of geocaches placed in parks). Details of the Geocaching activities were recorded and logged within the Geocaching site. This additional participation in the activity is significant as finding a single geocache can sometimes take upwards of an hour in a single trip or even multiple trips. It also provided valuable opportunity to reflect on the broader findings to understand how they should be applied specifically to location-based games.

Utilizing findings from all three of the above research stages, we recast our initial findings about Geocaching to specifically focus on creating and orchestrating scalable locationbased games. Our results are organized into two main sections, Game Content Creation and Game Monitoring \& Orchestration. Within each of these sections we outline a series of interrelated lessons for location-based game design that we believe have helped make Geocaching a scalable location-based game.

\section{Game Content Creation}

Geocaching is ultimately a player-created game and this was the case even from its inception [14]. Groundspeak Inc. and Geocaching.com directly facilitate the game of Geocaching with their servers and web infrastructure. They also supply guidelines and standards for the types of caches people can create and roughly where they might be placed. These rules are focused on ensuring player and non-player safety (e.g., caches cannot be placed on military installations, potential terrorist targets, bridges, or railway tracks) and designed to avoid saturation of caches in any one area (e.g., caches must be placed at least 0.1 miles away from each other). Yet aside from this, it is the players themselves that actually create the game of Geocaching for other players. They do this by creating and hiding caches. All caches are reviewed by volunteers-often other geocachers with a designated role assigned by Groundspeak - to ensure they meet the guidelines and rules, but given the flexibility in the rules, geocachers have a large degree of flexibility in how they construct the game of Geocaching. We found that there were several ways in which this was important.

\section{Lightweight Creation}

Geocache creation is ultimately simple and lightweight (if geocachers want it to be). One simply needs to get a container, place it in a location, record the GPS coordinates, write a brief description for the geocache location on a web page, and then submit it to Groundspeak volunteers. In fact, this process is often shorter than the time spent waiting for the geocache to be approved by volunteers (approval typically takes between one and five days). The result is a large variety of containers being used, ranging from repurposed Tupperware ${ }^{\circledR}$ containers, to magnetic key holders, to ammunition containers (Figure 1). We also see a large variety of locations. For example, Rochester, NY has a large number of urban caches placed in mall parking lots, small neighborhood 

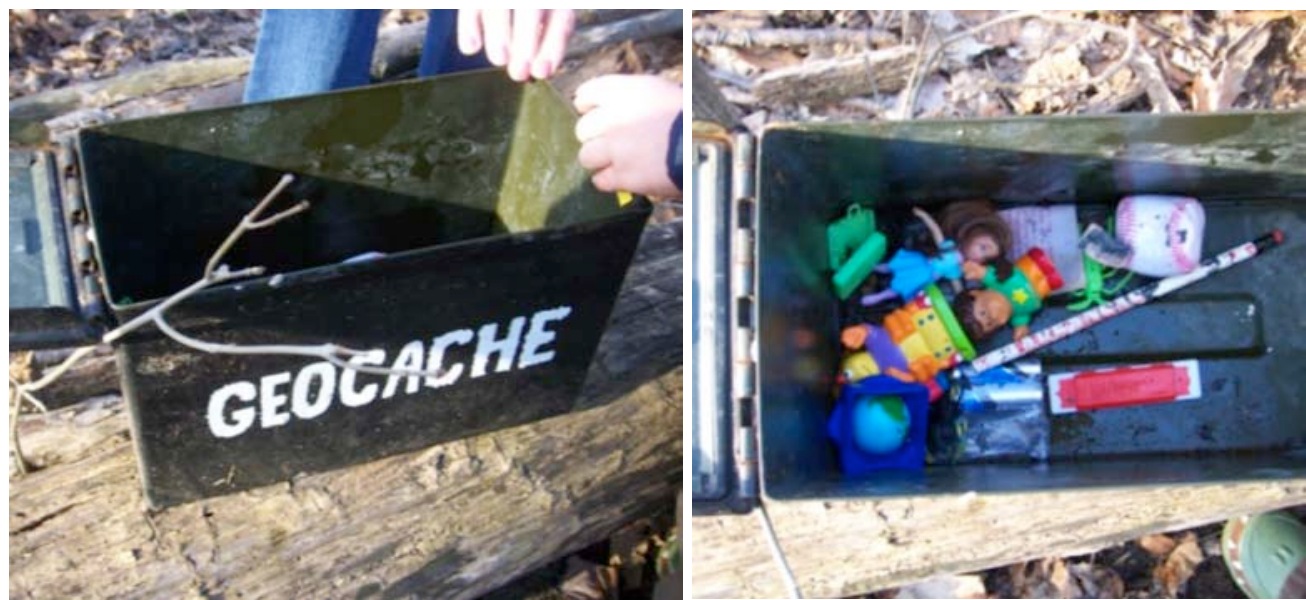

Figure 1. A traditional geocache made out of an ammunition container.
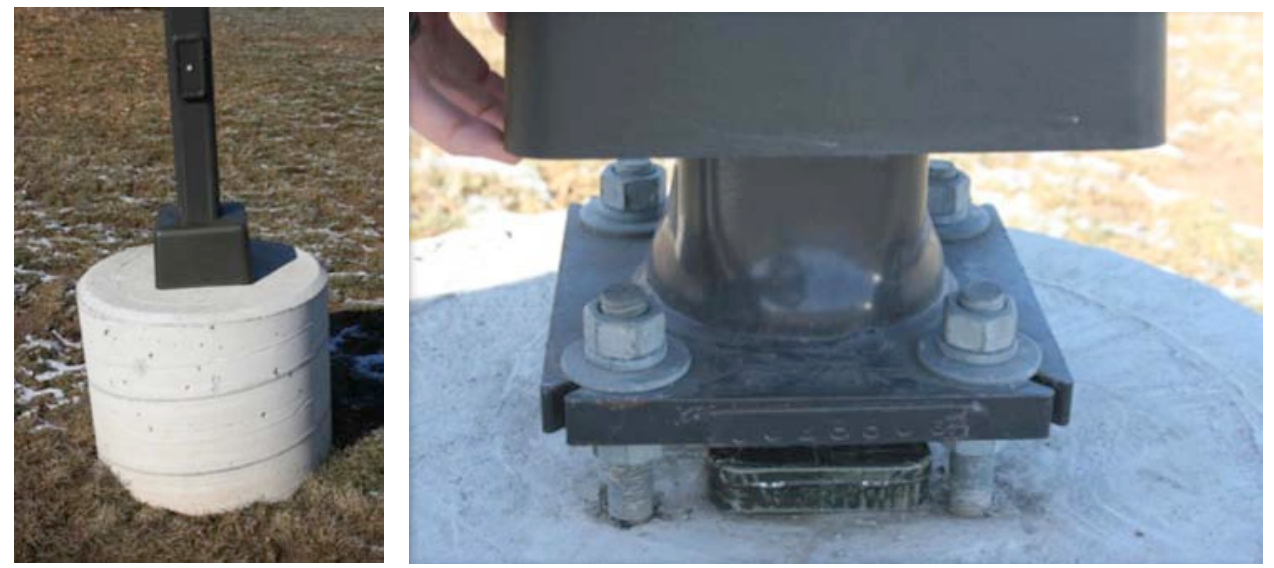

Figure 2. A lightweight cache creation in Rochester, NY.

parks, or other areas easily accessible to one driving up within a few meters of the cache location. Figure 2 shows one such "cache and dash" that we call the "Light Post Hide." At the edge of a hotel parking lot is a light post (Figure 2, left). Lifting up the base of the light post (Figure 2, right) reveals an "Altoid tin" (a candy mint container) repurposed to be a geocache container with green camouflage tape wrapped around it. Inside the container is a stack of papers constituting the logbook. We do not know how long it actually took the owner to create and hide this cache, but our own comparative geocache hides suggest that it could have taken as little as an hour to complete.

Lightweight creations are important for a number of reasons. First, since geocaches can be easy and lightweight to create, it means that the number of geocaches available for others to find can increase dramatically with only a small amount of effort by players. Second, for the creator of the cache, lightweight creations provide them with an easy way to get more involved in the game. Finding caches as a player is rewarding, yet creating them is additionally compelling and makes many players feel more "a part of" the game and responsible for it. Third, lightweight creations are important for they can often be easy to find. For example, the Light Post Hide could be found in less than a minute once arriving at the general cache area, if one knows that many Rochester, NY caches are hidden in light posts and searches there (we discuss this "sense of 
knowing" in more detail later). Such "cache and dashes" let people collect a large number of caches quickly and become "addicted" to the rush of hunting and finding.

Overall, the lightweight creation possibilities of Geocaching are one of the mechanisms that we believe have made Geocaching scale to a large number of areas and a wide player base. They have helped make it so there are a lot of geocaches available because they are simple to create. Our first lesson reflects this:

Lesson 1: It is easy and lightweight for players to create game elements, even from their onset of participation, within a predefined set of game rules.

Of course, there are challenges related to this lesson. Like many things, the benefit of lightweight creation does not come without risk. Because geocaches are so easy to create and hide, one may do so without thinking deeply about the type of experience it might create. Thus, lightweight creations might be poorly hidden and susceptible to being "muggled" (the stealing of geocaches by non-players called "muggles"), not hidden in interesting places, prone to weathering (e.g., the container is not waterproof), or too easy to find rendering the intrinsic reward for finding them to be minimal. A survey respondent comments on this:

"I followed the suggestions on the website about having experience before placing a cache. I was almost at 200 finds before I put out my first one. I learned early on that it's very annoying to go look for a cache that is not well done or the coordinates are off. I waited until I felt I had something to contribute to the game before jumping in." - Survey Respondent, Female, Age 55, $U S A$

A geocache in Greater Vancouver, BC, that we call "Root Hide" illustrates one example of a "poor" hide created by a newcomer after only finding five geocaches. The cache is a small repurposed pill bottle hidden in exposed roots at the base of a tree in a small forested area next to a local children's park. Within the first three months of its placement, the cache went missing twice and took the owner approximately six weeks to replace each time. When the cache was there, cachers reported its location to be approximately 15-20 meters away from the given GPS coordinates. This is quite far given the typical accuracy of GPS to be within a couple of meters. Certainly then, geocaches like Root Hide require additional monitoring and orchestration as part of the game of Geocaching to ensure quality. We return to this topic later in our results. 

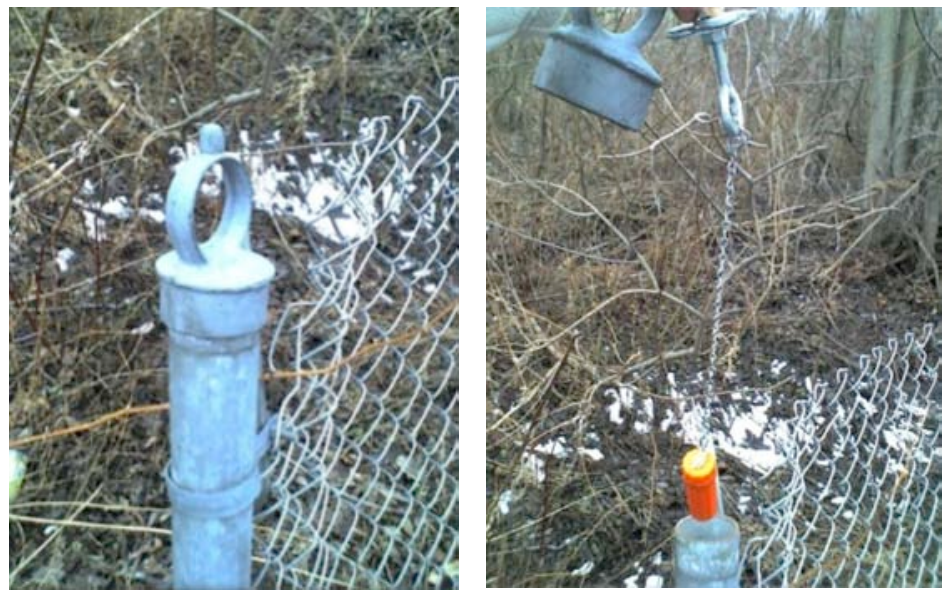

Figure 3. An elaborate cache creation in Rochester, NY.

\section{Elaborate Creations}

Many geocachers will also go to great measures to create and hide geocaches for others. Here they go beyond what one would do for a lightweight cache. This has resulted in a large range of rich and diverse creations that we call elaborate creations. For example, a geocache in Greater Rochester, NY, that we call "Fence Hide," can be found in the fence at the edge of a park containing multiple baseball diamonds. Figure 3, left, shows the fence post containing the cache, and unbeknownst to most, Figure 3, right, shows the hidden location of the cache within the fence post. The orange waterproof matchstick container holding the logbook is attached to a chain that in turn is attached to a hook and cap for the fence post. The cache creator has paid great attention to detail to construct this cache: he found a fence post with a cap that has come loose (many are held together with cement or are too tight to remove), found a waterproof container small enough to fit in this specific fence post, purchased chain and a hook, and attached the chain to a new cap that fits perfectly across the diameter of the fence post's opening.

Creation of such elaborate caches can take weeks or even months to complete with copious amounts of thought and planning. We also saw a variety of elaborate caches that differed in terms of what made them elaborate. Some, like the Fence Hide example, were elaborate because their container was carefully constructed for a particular location. Others had simple containers, yet geocachers were required to solve puzzles in order to figure out the final coordinates. These might involve answering questions about a location, or more general information around a particular theme. For example, one geocache we found required us to listen to the opening seconds of instrumental songs and figure out the song's titles. These titles pointed to numbers, which were then mapped to digits in the location's GPS coordinates. Other elaborate caches were more educational in nature and provided unique information about an area. For example, one survey respondent described how she and her husband created geocaches focused on describing different types of trees. 
Like lightweight creations, elaborate creations are also very important to Geocaching as they offer highly rewarding experiences as a part of gameplay. First, elaborate creations provide opportunities for cachers to be creative and create caches that they are especially proud of. When we asked respondents about their favorite hide, many said they preferred ones that were especially challenging to make. Second, cachers don't necessarily know when they are about to find an elaborate cache and so there is added suspense or mystery, and, in turn, added intrinsic reward if found. When we asked respondents about their favorite geocache find, many said they preferred to find elaborate creations. Two survey respondents commented:

"There is a cache in CO which was hidden in a bird house which was about 25 feet in the air and there was a cable which let the cache down. Very cool cache because it was up in the air and very creative." - Survey Respondent, Male, Age 20, Colorado, USA

"One of my favorites was one that had me puzzled for a while. In the end I figured out that you had to get water and pour it into a pipe that would make the cache float to the top. But you had to hold your finger on a hole at the bottom to stop the water from flowing out." - Survey Respondent, Male, Age 54, Canada

Overall, the elaborate caches provide richness to Geocaching that is serendipitously revealed to cachers, sometimes when they least expect it. Our second lesson reflects the need for elaborate creations, which can draw large numbers of players into the game because of the additional level of excitement and reward.

Lesson 2: It is possible for players to construct more elaborate game elements to increase enjoyment and richness in the game.

Certainly all caches cannot be elaborate creations or the game would become overly challenging. For this reason, the game needs both lightweight caches offering quick reward and gratification (for both hider and finder) and elaborate caches offering richer excitement and increased feelings of gratification.

\section{Game Customs}

Although there is an official set of rules to how geocaches are created, an implicit set of customs has evolved through user practices. Such cache customs are important. First, they help preserve the norms of Geocaching by defining the types of caches that are created, their contents, and where they are placed. Thus, even though cache creation is typically quite flexible, as previously described, the evolved customs offer a counterbalancing mechanism for consistency. This ensures that caches are similar enough between locations that they fit the basic practices of the activity. Cache creators are not required to follow customs, yet we found that they often do. 


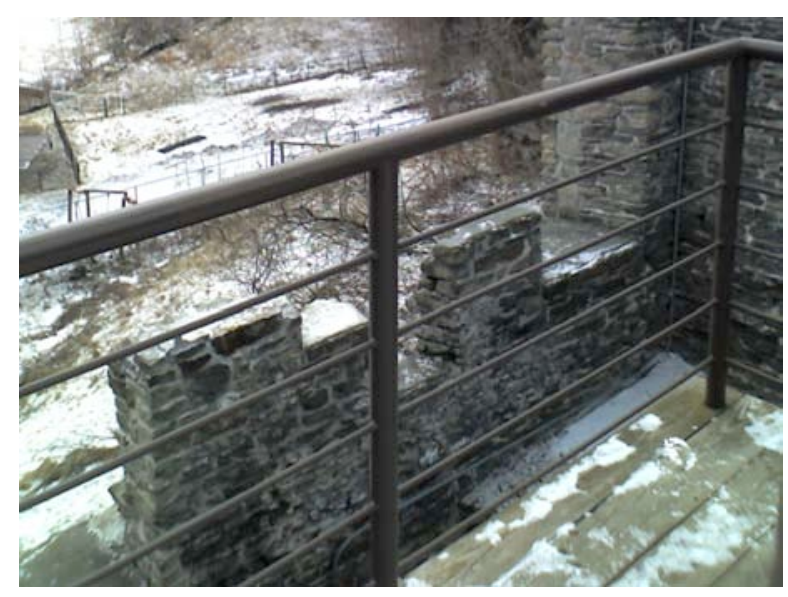

Figure 4. A geocache placed on a metal railing.

Second, cache customs help players find geocaches. Cachers can recognize a cache when they find it and know what to look for. This is important as cache containers often look like everyday objects (e.g., film canisters, Tupperware ${ }^{\circledR}$, trash). For each unique cache that people find or are told about, they build on their understanding of the activity and, in turn, the customs. For example, cachers might find a new style of container (e.g., plastic vs. metal) or notice a new method for attaching a cache container to an object (e.g., tied to a tree, magnetized to a light post or bench). Over time, they are likely to become better geocachers as a result and be able to find caches more quickly. Thus, the learning of cache customs creates a level of "geosense" that cachers can use to help them find caches.

Figures 4 and 5 shows two common types of situations faced by geocachers. Figure 4 shows the location of a geocache placed at a historic site in Rochester, NY. Prominently shown in the image is a metal railing. While approaching this railing, an experienced geocacher would recognize the metallic nature of it and realize the cache is mostly likely to be a magnetic case of some kind. Cachers accustomed to this area (Rochester, NY), would also recognize that a large number of urban caches in the city are created using magnetic key holders. Sure enough, the cache is a magnetic key holder attached to the bottom of the railing - though it is unfortunately out of view in the figure. In Figure 5, we see a tree with a series of twigs lined up horizontally at the base of the tree. An experienced geocacher approaching this location would recognize that twigs are not often lined up in such an organized fashion and this is likely the work of a fellow geocacher. Sure enough, the cache is an ammunition container sitting at the base of the tree with the twigs placed on top of it to hide it.

Like all customs or norms, Geocaching customs evolve. Geocachers continually try to push the bounds of the activity to create novel caching experiences. For example, when we first began our participation, the smallest geocaches that were readily hidden were micro containers, about the size of a magnetic key holder (10-15 $\mathrm{cm}$ long by 5-10 $\mathrm{cm}$ wide). Within a year of participating, it was not uncommon to find a cache container as small as a nut from a screw (with a very tiny piece of paper rolled up for a logbook). These are now known as "nano containers." Containers have also evolved with new forms of camouflage. Again, early on in our participation, 


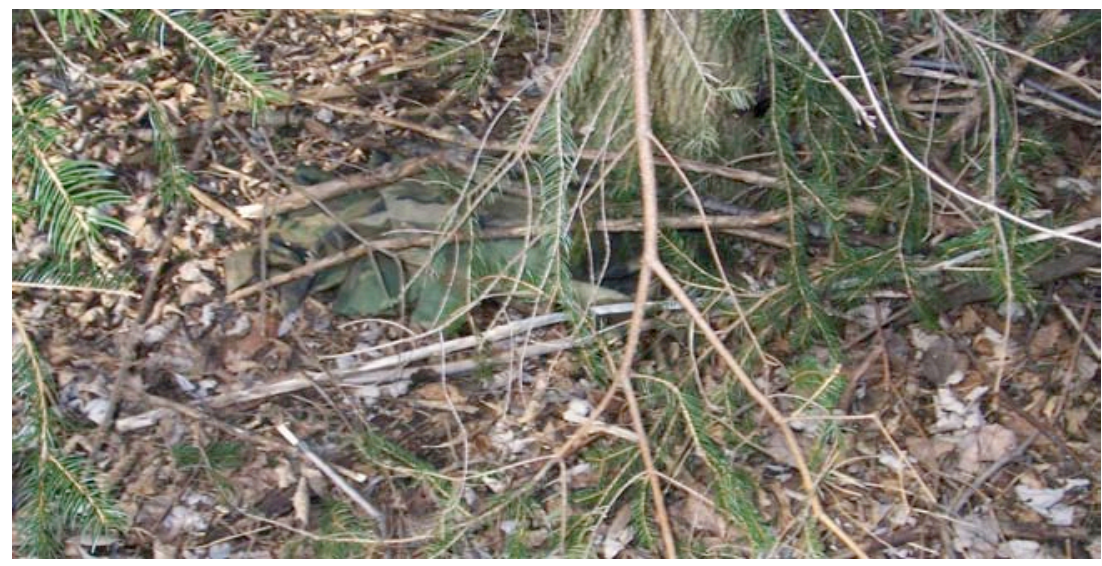

Figure 5. A geocache placed at the bottom of a tree underneath twigs.

a cache hung in a tree might be camouflaged with green or black tape wrapped around a repurposed pill bottle. Now cache containers hidden in trees may be embedded within objects typically found in trees like pinecones, birds nests, or branches. New or unique cache styles that push the bounds of Geocaching begin as being novel to players. Over time, they become the norm, and the cycle continues.

Overall, customs are important for maintaining game consistency and allowing players to understand the nature of the game. Our third lesson reflects this:

Lesson 3: It is possible for players to understand the customs of the game and evolve these over time so the game can grow and provide new types of game experiences.

Again, there is a risk with this lesson. Cachers cannot simply be allowed to create anything and call it a geocache. Caches should always adhere to the core attributes of the game otherwise there is a chance that they may be unrecognizable as geocaches or the act of finding them may not be recognizable as Geocaching.

\section{Game Monitoring \& Orchestration}

Geocaching is an activity that occurs at many hours during the day, and on a variety of days during the week. Players do not often have set schedules for Geocaching and many interweave the activity throughout their daily activities [23]. Because of this variability in play, one might imagine that there is little in terms of orchestration or monitoring of game activities aside from volunteers reviewing and approving new caches. Yet we found the contrary. Geocaching is orchestrated and monitored on an ongoing basis as players hunt for caches and use the Geocaching web site. After a cache has been hunted for (either found or not), cachers post logs of their experiences to the geocache web page. By default, cache owners receive emails when another cacher writes a $\log$ for one of their caches. Within this structure, we see several main activities occurring: monitoring of caches, monitoring of people, and community maintenance of caches. 


\section{Monitoring Caches}

Rather than visiting the caches themselves to check on them, the vast majority of cache creators rely on the logs that people write about their cache experiences to help maintain them. That is, cache creators generally rely on others to find their caches, log their experiences online, and report any problems. Creators then read these logs and, if problems are reported, will physically fix the cache as needed. In this way, the players themselves actively monitor the game components.

"I mainly pay attention to the online logs. I do not physically go out and check my caches unless someone mentions there is a problem." - Survey Respondent, Male, Age 29, Illinois, USA

The Geocaching website supports several types of logs including Found It, Did Not Find (DNF), Needs Maintenance, or Post Comment. The severity and specific use of the different log types varies, but, in general, all allow one to monitor the state of game elements. This allows cache owners to receive feedback on the status of their cache and fix it if needed. For example, after receiving this Needs Maintenance log, the cacher owner would likely physically go and replace their log book:

"One of many finds while camping for the weekend in [local park] with [cacher name]. There was about half an inch of water in the cache box bottom and the log book was too saturated to sign." Needs Maintenance log from New York, US

Other cachers can also select which caches they want to receive email notifications for when new logs are posted to a cache's page. This allows them to monitor specific caches of interest to them. For example, they might monitor a cache that they previously could not find to see what future seekers say about it, or if the owner decides to replace a missing cache. Some cachers also actively monitor caches that they helped create but are not listed as the designated owner.

Prospective searchers who may be deciding whether or not they should hunt for a particular cache also use logs. For example, if a Needs Maintenance log (like above) has been recently posted, they may choose to not hunt for the cache, as this "part" of the game of Geocaching is not currently operational. On the other hand, if they see a Found It log, like below, they may choose to look for the cache since it is available:

"One of the last caches of the day with [cacher name]. A nice walk across the ballfield, but the dew made the incline rather slippery.. we both went down. We found the cache uncovered - we signed the log and covered it better than found. Thanks for the hide." - Found It Log from New York, USA

The act of monitoring caches is lightweight. The creation of logs is a simple activity done by players after they hunt for caches. Most cache logs contain short descriptions of the hunting experience, as shown above, and take little time to complete. And, perhaps more interesting, is that often players are posting logs for reasons other than monitoring caches. In the case of Found 
It logs, they want to be rewarded for their find so must post a log in order to score a "point." Thus, the act of monitoring caches is carefully constructed such that it is more about participation than it is about monitoring. In cases where cachers want to provide more information about monitoring, they can. That is, they can offer opinions on the precise accuracies of the GPS coordinates, the quality of the container and its contents, the difficulty or terrain rating, and the susceptibility of the container and its contents for becoming easily damaged or muggled. For cache creators, reviewing caches is also a simple activity as they are short and easy to read. One also does not need to read all logs and can often simply look to see if the log type is Needs Maintenance or if several Did Not Find logs have been posted (suggesting that the cache might be missing).

Overall, this illustrates the simple ways that player activity logging can be used to support monitoring game elements such as caches. Our fourth lesson points to this:

Lesson 4: It is possible for players to report on and monitor game elements through lightweight activities

Here the challenge is that monitoring activities must be minimal and offer reward to players. In the case of Found It logs, there are certainly rewards (more points) and thus no disparity between work and benefit [13]. Yet in the case of other log types, there are no rewards as is the case with Needs Maintenance logs, or even negative rewards, in the case of Did Not Find logs. For example, many geocachers do not report Did Not Find logs initially (but may post them after several attempts to find the cache) because it represents negative experiences where one was unsuccessful in their activity. The good thing about Geocaching's structure is that, given the large number of players, even if one individual player does not report issues with a cache, it is likely that another player will within a few days or weeks. If all players had to actively concern themselves with monitoring activities all the time in addition to gameplay, the experience of the game would most certainly change and players could easily become distracted and full time orchestrators rather than players.

\section{Monitoring Players}

Similar to monitoring game content, players also actively monitor others (as part of the game and not in a voyeuristic sense). These may be friends who they routinely cache with or they might be strangers. Monitoring of players mostly occurs, again, in the Geocaching logs on each cache's page. Each log includes the cacher's name, how many finds they have, and a link to a profile page for the cacher. With enough participation, over time, many cachers begin to recognize the names of frequent cachers. For example, the following log was posted for one of our cache hides. Here the cacher is commenting on the first person who found the cache and asking for a hint as to where it is:

"I think if we are really, really nice to "[cacher's name removed]" we might be able to convince her to put an " $X$ " where she was standing." - Comment log from Vancouver, BC 
Sometimes players will happen to see other cachers on a hunt. Given the large number of caches, their spread across areas, and the variability in times that people cache, cachers typically only meet up with others serendipitously when looking for caches that are freshly released. Premium members can sign up to receive email notifications on newly published hides. Such emails often create a frenzy for claiming the "first to find" prize or bragging rights. In other situations, meeting up with other cachers is rare, but it does sometimes happen. The following log represents one such occasion:

"My instincts had me track down another cacher as he was leaving and convincing him to return to look again, good thing too as he was the one to eventually spot it :D Thanks for the hunt!" Found It log from Vancouver, BC

Cachers also directly contact other players (strangers) through private messaging within the site. Cacher profile pages contain details about each player including statistics on their finds. There is also a link to send a message to the cacher through the Geocaching site. Throughout our participation we have contacted over twenty different cachers through the site and found them to be incredibly responsive. In turn, we have also received numerous questions about caches we have hidden. In most cases, people are actively seeking out additional hints or writing private messages to let the owner know the cache needs repair.

Our fifth lesson points to this ability to monitor other players in Geocaching:

Lesson 5: It is possible for players to monitor and interact with other players through lightweight online activities.

Again, monitoring activities must be simple and lightweight and there also must be a balance between monitoring and privacy. Geocaching does this effectively by utilizing user names as opposed to real names and messaging with other players can be done entirely through the online system. There is an option to reveal your own email address and interact with other players using it, and some do, but this is optional.

\section{Monitoring Non-Players}

As mentioned, non-players in Geocaching are called "muggles" and players will also actively monitor them. The goal is to ensure that geocaches are not muggled (stolen) and that muggles do not "catch on" to the game and begin to ask questions. Thus, geocachers will carefully watch for non-players when they are hunting for a cache to ensure they don't see them looking, finding it, or signing the logbook. When players posts logs to the Geocaching site, they will sometimes report on muggle activity near a cache. The following logs illustrate this:

"Spent a while looking for this before a group of muggles chose to sit down right next to me and drink their cider. Will have to try again." - Did Not Find log from Vancouver, BC 
"Well, I'm surely in fine company with this DNF. I had shinnied up the maple tree and was hanging out over the construction hole when security arrived. One guy actually had a straightjacket in hand, go figure. After giving them my best geo-speech, they relented and said I could stay if I kept my feet on the ground. Back to hands-and-knees to no avail. I shall return." - Did Not Find log from Rochester, NY

Monitoring non-players can be highly important to report behaviors that may affect the game, such as frequent muggle activity near a particular cache. This knowledge can help future players know how much "stealth" they need to use when hunting and further understand the status of a cache if it appears to be missing.

Our sixth lesson reflects players' ability to monitor and report on non-player activities:

Lesson 6: It is possible for players to monitor non-players and share this information with other players.

In this case, the challenge is that non-player monitoring and reporting is a custom that has evolved to become acceptable and desired practice. Nowhere in the logging mechanisms does it say, "report muggle activity," or the like. Instead, over time, players have learned that it is important to watch that muggles don't see them geocaching, and, if some do, it is important to record and tell others about it. New players to the game may certainly not realize this, leaving non-player monitoring mostly in the hands of more experienced players.

\section{Maintenance}

Geocaching players also actively maintain game elements as they participate. Here the acts are beyond just participation and include geocaches created by other players: some geocachers perform activities to ensure the game elements are in place and fine for others to find. Even though they generally take little time to perform, people receive little or no reward for these acts aside from positive feelings associated with helping out the community. This further highlights the fact that cachers actively feel a responsibility for providing feedback about cache states and maintaining caches such that others can enjoy them. The following log describes this:

"Found the log soaking wet with no baggie to protect it. I took it with me so it could dry out. Will replace it ASAP and post another note when it is in place again." - Cache log, New York, USA

In these instances, some cachers will carry materials with them that are likely to be needed for cache repair, e.g., logbooks, extra containers, plastic bags. This is interesting for it shows that inplace maintenance is often preplanned, thereby signaling a premeditated feeling of responsibility for the game and game elements.

"We bring a first aid kit, a cache repair kit, some pens, notbooks [sic] and extra batteries. Also, gloves, extra socks, wet naps and ziploc bags." - Male, Manitoba, Canada 
Sometimes caches become completely abandoned. We suspect this happens most often because the cacher is no longer interested in playing the game. In situations like this, the volunteer reviewers might step in and "archive" a cache (remove it from the system) if they notice a geocache has been flagged by others as needing maintenance and the owner has not responded after a given period of time. There is no set time frame for this; it is at the discretion of the reviewers. The following log describes the action taken by a volunteer reviewer in one such occasion.

"As there's been no cache to find for months, I'm archiving it to keep it from continually showing up in search lists, and to prevent it from blocking other cache placements. If you wish to repair/replace the cache sometime in the future, just contact us (by email), and assuming it meets the guidelines, we'll be happy to unarchive it". - Cache Log by a New York state Reviewer

In other situations, the reviewers may not step in and a cache page may sit for several months or more when the cache has clearly gone missing. In cases like this, other players may step in. For example, a cache that we call "Fast Food Hide," located in Greater Vancouver next to a fast food restaurant, went missing for approximately six months. During this time, the cache received posts from 13 different cachers who all suggested the cache was missing and should be fixed or archived. Volunteer reviewers took no action and the cache owner was unresponsive. After waiting what appeared to be an acceptable time period, one cacher replaced the cache himself and wrote this $\log$ :

"Well this one is very obviously missing with no owner maintenance, and it seems like it's been just about impossible to get it archived ...... What to do??? Well I decided to just replace it myself, in the posted coords. it is a micro, camo container, if your [sic] standing around the middle of the corner parking stall, you can reach it in between a few pieces of broken concrete." - Cache Log in Vancouver, $B C$

Our seventh and final lesson points to players' ability to help maintain game elements:

Lesson 7: It is possible for players to maintain the game elements that have been created by others and suggest when they should be removed from the game.

There is a challenge that arises in these cases and this mostly relates to who is the actual owner of a particular cache and the level of control others have. Non-owners can only interact with the physical cache container and the log pages. They cannot actually update the page for a cache for which they don't own. For instances like Fast Food Hide, the cache owner still maintains the cache's page even if s/he has stopped playing the game. Players who now maintain the physical cache in the future can only post new details about it through the logs, as was the case in the log shown above. Without consent of the cache owner, the cache can also not be "adopted" or transferred to another cacher. In this way, the structure of Geocaching does not actually permit 


\begin{tabular}{|c|c|c|c|c|c|c|c|c|c|c|}
\hline & \multicolumn{2}{|c|}{ Type of Play } & \multicolumn{3}{|c|}{ Types of Content } & \multicolumn{2}{|c|}{$\begin{array}{c}\text { Player } \\
\text { Interactions }\end{array}$} & \multicolumn{3}{|c|}{$\begin{array}{c}\text { Who Creates } \\
\text { Content }\end{array}$} \\
\hline & Fixed & Continual & Light & Elaborate & Complex & Sync & Async & Admin & Player & Auto \\
\hline Ambient Wood & $\checkmark$ & & & & $\checkmark$ & $\checkmark$ & & $\checkmark$ & & \\
\hline Savanaah & $\checkmark$ & & & & $\checkmark$ & $\checkmark$ & & $\checkmark$ & & \\
\hline Treasure & $\checkmark$ & & $\sqrt{5}$ & & & $\checkmark$ & & $\checkmark$ & & \\
\hline Feeding Yoshi & & $\checkmark$ & $\sqrt{ }$ & & & & $\checkmark$ & & & $\checkmark$ \\
\hline Uncle Roy & $\checkmark$ & & & & $\checkmark$ & & & $\checkmark$ & & \\
\hline CYSMN? & $\checkmark$ & & $\checkmark$ & & & & & & & $\checkmark$ \\
\hline EyeSpy & & $\checkmark$ & $\checkmark$ & & & & $\checkmark$ & & $\checkmark$ & \\
\hline Anywhere & $\checkmark$ & & $\checkmark$ & & & & & $\checkmark$ & & \\
\hline Blowtooth & & $\checkmark$ & $\sqrt{ }$ & & & & & & & $\checkmark$ \\
\hline Geocaching & & $\checkmark$ & $\checkmark$ & $\checkmark$ & & $\checkmark$ & $\checkmark$ & & $\checkmark$ & \\
\hline
\end{tabular}

Table 1. Variations in location-based game design (sorted by year of publication).

easy transfer of ownership in problem instances. Instead, players must find workarounds (utilizing the logging system).

Issues of ownership also arise in more normal gameplay situations where players create caches together as a group, which is frequent. Caches can only be associated with one cacher's profile as owner, so group efforts to create or maintain a cache go unrecognized unless they are reported in the logs. This, again, is a workaround. Overall then, the linkage of a cache to a single owner may instill lesser feelings of ownership over a cache even in cases where others clearly helped create the cache or maintain it.

\section{Discussion}

The goal of our discussion section is to provide researchers and designers of location-based games with a better sense of how they might utilize the lessons from Geocaching, if at all, in their own game designs. Certainly it is the case that not all types of location-based games lend themselves to be created and orchestrated in a manner similar to Geocaching. However, some can, and our discussion unravels this. We also recognize that our findings are qualitative and there are no clear causal relations between our lessons and the actual scalability of Geocaching. That is, there could certainly be other reasons beyond the lessons we provide that are the reason why Geocaching can be 1) played and orchestrated over long periods of time in a variety of locations, and 2) played by a large number of players (e.g., hundreds or thousands of people). The lessons, when applied to other location-based games, could also yield little to no effects. Regardless of these issues, the lessons from Geocaching point to practices that are at the core of the game and one can speculate with reasonable certainly that they are one large piece behind Geocaching's growth over the last decade. 


\section{Attributes of Location-Based Games}

To begin, we have analyzed a number of different location-based games that have been presented in academic papers over the last decade and placed them in Table 1 for comparison. Games were selected based on their prominence in the literature and certainly there are more in existence than those we selected. Table 1 compares the games across four main properties: types of play (fixed duration/time vs. continual), types of content (in terms of the effort required to create it: lightweight vs. elaborate vs. complex), player interactions (either synchronous or asynchronous), and who creates content (game administrators, players, or auto-generated content by the game). Certainly there are other attributes that one could use to differentiate LBGs, however, we have found this current set helps to illustrate the applicability our lessons to location-based games better than others.

Type of Play. Location-based games differ based on when and where they can be played (Table 1, Type of Play). Games based on fixed play are only available when the game is running and are tied to specific locations. Moving them to other locations requires a large amount of effort [9]. For example, in the game, Savannah, children learn about animals by roleplaying as lions in a large field where they have to find resources to survive [8]. Mobile phones carried by the children display location-based content as they move around. This content is very carefully mapped between the real world and virtual world displayed on the mobile devices [10] and, as such, it would be difficult to recreate this game in another location. The game is also only available during a specific period of time, in this case, class time [8]. On the other hand, some games allow continual play where the game is available at any point in time and could be played in conceivably any location without additional effort. For example, in Feeding Yoshi players score points for finding unsecured and open wireless access points [9]. This activity was found to be done at any point in one's day and in a variety of locations [9].

Type of Content. Location-based games can also have content this is lightweight, elaborate, or complex in terms of the effort required to create it (Table 1, Types of Content). As can be seen from Table 1, many location-based games have content that is comparatively (and likely arguably) lightweight and easy to create. For example, in EyeSpy, players can tag locations with the simple act of capturing an image on a mobile device [3]. In Can You See Me Now? (CYSMN) - a game of tag between an actor in the streets and an online player-the content is the position of the actor, which is easily generated as the actor moves. Geocaching, one could argue, allows people to create content that is more difficult to produce than this, and richer in terms of the experience that is offered; thus, it is elaborate content. On the other hand, some games contain content that is even more elaborate and more difficult to create than even Geocaching's elaborate creations; we call this complex content. For example, in Ambient Wood, students traversed a woodland area —embedded with location-based content— to learn about their environment [27]. For example, PDAs provided students with images of plants nearby and other embedded objects such as wireless speakers played nature sounds when students were near. Other games such as Uncle Roy, which could be considered performance art, have complex content interwoven with carefully crafted narrative. 
Player Interactions. Location-based games can have any number of players participating depending on their design. In Table 1, "Player Interactions," we list how players interact with one another, if at all, as part of a game. If the game involves only a single player playing with no interactions with other players, we show no interactions (no checked boxes). Uncle Roy [7], CYSMN [6], and Anywhere [3] all have an actor working synchronously with a player, but this is technically never another player; these are thus not included as player interactions. For other games, multiple players work together or compete in the game, either synchronously (labeled as "Sync" in Table 1) or asynchronously (labeled as "Async" in Table 1). For example, in the case of synchronous interactions, in both Ambient Wood and Savannah, small groups of students work together to play the game where they synchronously collaborate with each other. On the other hand, in Feeding Yoshi [4] and EyeSpy [3], large numbers of players participate and compete with each other but in an asynchronous fashion.

Who Creates Content. Content for location-based games can either be pre-planned prior to game play or it can be created "on the fly" as part of the game. Uncle Roy All Around You, Ambient Wood, Savannah, and Anywhere all have their content pre-planned and created by game administrators (labeled as "Admins" in Table 1), which clearly would have taken a large amount of time to carefully craft. On the other hand, content is created in real time for the other games. For Blowtooth [19] and Feeding Yoshi [4], elements in the environment (wireless access points, other people with PDAs) automatically (labeled as "Auto" in Table 1) create game content. EyeSpy [3] on the other hand actively involves players (labeled as "Players' in Table 1) generating content as they tag locations. The locations may pre-exist, but without the players' work to tag them, the game is not nearly as compelling. Geocaching fits within this last grouping.

\section{Applying the Lessons from Geocaching}

Our results provide seven lessons from Geocaching that can be used to understand how game designers might consider creating scalable location-based games. We step through each of these and discuss what types of games they might best apply to.

1. Lightweight Creations: In Geocaching, it is easy and lightweight for players to create game elements, even from their onset of participation, within a predefined set of game rules. This lets the game grow quickly and include a large group in an important activity: game element creation. Our results also revealed that lightweight creations can be problematic if care and effort is not taken to ensure the content is of a good quality. In Geocaching, this meant that containers were sometimes stolen, weathered, or too easy to find. Yet in Geocaching players actively monitor game content to fix or avoid situations like this. For this reason, we suggest that this lesson be applied in situations where there is some mechanism for active monitoring of content and reporting the removal of such game content. If there isn't, the game could suffer with large volumes of poorly created content.

It is also important to consider what the goal of the game is before deciding if it should allow users to create lightweight content. Games like Uncle Roy All Around [7], Ambient Wood 
[27], and Savannah [8] all contain complex game elements that are carefully constructed, created, and placed by game orchestrators. One could consider permitting lightweight creations when creating these types of games; however, it would likely take away from the purpose of the games in terms of the societal issues being explored (e.g., trust for Uncle Roy All Around You [7]) or educational elements being learned (Savannah [8] and Ambient Wood [27]). That is, to properly pursue these elements in depth, complex creations are likely necessary. It may also be the case that if players tried to create such elements themselves, they could easily miss the mark of exploring such issues because of a lack of understanding or knowledge.

2. Elaborate Creations: In Geocaching, it is possible for players to construct more elaborate game elements to increase enjoyment and richness in the game. Most geocachers enjoy hiding and finding elaborate creations above all others. Thus, we would suggest that when creating games that already support player-creation of lightweight game content (e.g., those similar to Feeding Yoshi [4], Blowtooth [19]), one consider permitting players to also create more elaborate game content. This would allow players to create content that is perhaps more compelling to find or offer new and interesting experiences, and, hopefully cause other players to continue to play the game longer term.

Games like Uncle Roy All Around [7], Ambient Wood [27], and Savannah [8] all contain fairly complex game elements already, even more complex than that of the elaborate elements in Geocaching. Like lightweight creations, it would be questionable to allow players to include elaborate creations (less than complex) as a part of this style of game.

3. Game Customs: It is possible for players to understand the customs of the game and evolve these over time so the game can grow and provide new types of game experiences. In Geocaching, this helps cachers hide caches for other people such that they are recognizable as part of the game of Geocaching. It also ensures content is consistent (i.e., addressing [26]'s concern of usergenerated location content). We suggest that this lesson should be applied to games that allow repeat or continual play over time. This will allow players to develop strategy [2] and it will also enable new content to be created that can help keep the game "fresh" and interesting to players over time. However, we caution against applying this lesson in games that are focused on education (e.g., similar to Savannah [8] or Ambient Wood [27]) or utilize secret content that players should not know about ahead of time (e.g., Uncle Roy [7]); these games are often those that are fixed to specific physical locations and times. Allowing users to learn the customs of these games would completely take away from the game's experience. Similarly, evolving the customs could prove to be problematic and take away from the game's educational or cultural goals.

4. Monitoring Game Elements: It is possible for players to report on and monitor game elements through lightweight activities. Geocaching allows players themselves to monitor the core game elements, the geocaches. This is done in real time as players hunt caches and check on them as they do so. However, the reporting structure for this is typically not real time; it happens 
asynchronously, after the fact. For many location-based games, this is not enough. In the case of games that are played over a fixed time period (e.g., similar to Uncle Roy [7], CYSMN [6], Anywhere [3]), game elements could be monitored by players through lightweight activities, yet reporting would need to be real time. Geocaching's monitoring structure would not work in this case. Games that are designed to be played continually (e.g., similar to EyeSpy [3]) could rely on mechanisms similar to Geocaching for monitoring game elements. There might also be cases where monitoring of game content is not even needed. For example, in Feeding Yoshi [4], if a Wifi hotspot (the game content) becomes inactive, there is no problem. That game element is simply not available, and nothing needs to be done about it. Thus, when considering the monitoring of game elements, it is important to consider if monitoring is in fact needed, and, if it is, does it need to occur in real time or is a historical record (like Geocaching) good enough.

5 and 6. Monitoring Players and Non-Players: It is possible for players to monitor and interact with other players through lightweight online activities. It is possible for players to monitor nonplayers and share this information with other players. Like the monitoring of game elements, players and non-players are similarly monitored in Geocaching in an asynchronous fashion via the logging mechanisms within the site. We suggest that Geocaching's style of monitoring is best suited for games that are the same as Geocaching in terms of the type of play and player interactions (e.g., games similar to EyeSpy [3], Feeding Yoshi [4]). That is, they should be games that are continually played over time where players interact asynchronously. For games that are played in a fixed time interval, or that have synchronous interactions between players, Geocaching's style of player and non-player monitoring may not provide enough detail. Perhaps the most compelling example is Can You See Me Now?. This game hinges on the constant monitoring of players. After all, it is a mixed-reality game of tag. As Capra et al. [9] reports, in games with dedicated play times, often continual connectivity is important for game administrators to properly orchestrate the game and track player locations. There are also cases where this lesson does not apply and monitoring of other players or non-players is not needed. For example, games that are designed to be single player like Blowtooth likely don't require such monitoring. Thus, game designers should think carefully about what level of player monitoring-synchronous, asynchronous, or none at all-is appropriate.

7. Maintaining Game Elements of Others: It is possible for players to maintain the game elements that have been created by others and suggest when they should be removed from the game. In Geocaching, since players are actively creating the game elements for others, in the case that these elements go awry, others can step in to ensure the game continues to be playable. This element is important for user-created content when games grow large or when players may stop playing. For this reason, we suggest this lesson is applicable for any location-based game that allows users to generate content as part of the game. The alternative is maintenance by the game administrators, which could easily become quite tedious when a game has grown to a large scale. An additional example of how this might be done is found in EyeSpy [3]. EyeSpy accomplishes 
game maintenance of others' elements by having players verify location tags [3]; in fact, this is the essence of the game.

\section{Conclusion}

Our studies of Geocaching have revealed the ways in which game players (geocachers) actively create game content, monitor and maintain the game elements created by other players, and monitor the players and non-players themselves. We have presented this as a series of lessons that should be thought about when designing or researching location-based games. We recognize that not all games are of the same genre, scope, and structure as Geocaching. Some are much more complex in nature and could even be considered performance art pieces with complex narrative interwoven amongst game play (e.g., Uncle Roy All Around You [7]). Yet there are also locationbased games that are similar to Geocaching in terms of their ability to be played at any point in time, their varied locations, and the ease at which content can be created by players themselves (e.g., EyeSpy [3], Feeding Yoshi [4]). In these situations and more, it can be valuable to reflect on the lessons found in Geocaching to understand how a location-based game can be designed to be scalable. Our analysis provides a first step in this direction.

\section{Acknowledgements}

We thank Eastman Kodak Company for funding our initial studies of Geocaching.

\section{References}

1. Adams, E. Fundamentals of Game Design, New Riders (2010).

2. Barkhuus, L., Chalmers, M., Tennent, P., Hall, M., Bell, M., Sherwood, S., and Brown, B. Picking Pockets on the Lawn: The Development of Tactics and Strategies in a Mobile Game, Proc. Ubicomp 2005, Springer (2005).

3. Bedwell, B., Schnadelbach, H., Benford, S., Rodden, T., and Koleva, B., (2009) In Support of City Exploration, Proceedings of the Conference on Computer Human Interaction, ACM Press.

4. Bell, M., Chalmers, M., Barkhuus, L., Hall, M., Sherwood, S., Tennent, P., and Brown, B. (2006) Interweaving Mobile Games with Everyday Life, Proceedings of the Conference on Computer Human Interaction (CHI 2006), Montreal, pp. 417-426.

5. Bell, M., Reeves, S., Brown, B., Sherwood, S., MacMillan, D., Ferguson, J., Chalmers, M. (2009), EyeSpy: supporting navigation through play, Proceedings of the Conference on Computer Human Interaction, ACM Press, pp. 123-132.

6. Benford, S., Crabtree, A., Flintham, M., Drozd, A., Anastasi, R., and Paxton, M. Can You See Me Now? ACM ToCHI, Vol. 13, No. 1, March (2006), 100-133. 
7. Benford, S., Crabtree, A., Reeves, S., Flintham, M., Drozd, A., Sheridan, J., and Dix, A. The Frame of the Game: Blurring the Boundary between Fiction and Reality, Proc. CHI 2006, ACM Press (2006), 427-436.

8. Benford, S., Rowland, D., Flintham, M., Hull, R., Reid, J., Morrison, J., Facer, K., and Clayton, B. (2004) "Savannah: Designing a location-based game simulating lion behaviour," Proceedings of the Conference on Advances in Computer Entertainment 2004.

9. Capra, M., Radenkovic, M., Benford, S., Oppermann, L., Drozd, A., and Flintham, M. (2005) The Multimedia Challenges Raised by Location-based Games, Proceedings of ACM's Multimedia Conference (MM 2005), ACM Press, pp. 89-95.

10. Chavez, D.J., Courtright, R., and Schneider, I. Over the River and through the Woods, Parks \& Recreation, 39, 4 (2004), 68-72.

11. Chavez, D.J., Schneider, I., and Powell, T. The Social Psychology of a Technology Driven Outdoor Trend: Geocaching in the USA, Proc. HICSS 2004, ACM Press (2004).

12. Geocaching, http://Geocaching.com

13. Grudin, J. Groupware and Social Dynamics: Eight Challenges for Developers, Communications of the ACM, 37, 1, ACM Press (2004), 92-105.

14. History of Geocaching, The, http://www.Geocaching.com/about/history.aspx

15. Kelley, M.A. Local Treasures: Geocaching across America. Santa Fe: Center for American Places (2006).

16. Ludford, P., Frankowski, D., Reily, K., Wilms, K., and Terveen, L. Because I Carry My Cell Phone Anyway: Functional Location-Based Reminder Applications, Proc. CHI 2006, ACM Press (2006), 889-898.

17. Ludford, P., Priedhorsky, R, Reily, K., and Terveen, L., Capturing, Sharing, and Using Local Place Information, Proc. CHI 2007, ACM Press (2007), 1235-1244.

18. Lindqvist, J., Cranshaw, J., Wiese, J., Hong, J., and Zimmerman, J. I'm the Mayor of My House: Examining Why People Use foursquare - a Social-Driven Location Sharing Application, Proceedings of CHI, ACM Press (2011), 2409-2418.

19. Linehan, C., Kirman, B., Lawson, S., and Doughty, M. Blowtooth: Pervasive Gaming in Unique and Challenging Environments, Proc. CHI, ACM Press (2010).

20. Magerkurth, C., Cheok, A., Mandryk, R., and Nilsen, T. Location-based Games: Bringing Computer Entertainment Back to the Real World, Proceedings of Computers in Entertainment, Vol. 3(3), July 2005.

21. McGonigal, J., Reality is Broken: Why Games Make Us Better and How They Can Change the World, The Penguin Press (2011).Neustaedter, C., Tang, A., and Judge, T., The Role of Community and Groupware in Geocache Creation and Maintenance, Proceedings of CHI 2010, ACM Press.

22. Neustaedter, C., Tang, A., and Judge. T, The Role of Community and Groupware in Geocache Creation and Maintenance, Proc. CHI 2010, ACM Press (2010). 
23. O’Hara, K. Understanding Geocaching Practices and Motivations, Proc. CHI 2008, ACM Press (2008).

24. O'Hara, K., Kindberg, T., Glancy, M., Baptista, L., Sukumaran, B., Kahana, Gil., and Rowbotham, J. Social Practices in Location-Based Collecting, Proc. CHI 2007, ACM Press (2007).

25. Putnam, R. Bowling Alone,Simon and Schuster (2000).

26. Reily, K., Ludford, P., and Terveen, L. Sharescape: An Interface for Place Annotation, Proc. NordiCHI 2008, ACM Press (2008).

27. Rogers, Y., Price, S., Fitzpatrick, G., Fleck, R., Harris, E., Smith, H., Randell, C., Muller, H., O’Malley, C., Stanton, D., Thompson M., and Weal, M. (2004) Ambient Wood: Designing New Forms of Digital Augmentation for Learning Outdoors, Proceedings of IDC 2004, ACM Press.

28. Rollings, A. and Adams, E. Andrew Rollings and Ernest Adams on Game Design, New Riders (2003).

29. Salen, K. and Zimmerman, E. Rules of Play: Game Design Fundamentals, MIT Press (2004).

30. Salovaara, A., Johnson, M., Toiskallio, K., Tiitta, S., and Turpeinen, M. Playmakers in Multiplayer Game Communities, Proc. ACE 2005, ACM Press (2005).

31. Stanley, K., Livingston, I., Bandurka, A., Kapiszka, R., Mandryk, R. (2010) PiNiZoRo: A GPS-based Exercise Game for Families, Proc. Future Play, (2010), 276-279.

32. Strauss, A. and Corbin, J. Basics of Qualitative Research, 2nd Edition. Chapter 8, Open Coding, Sage Publications (1998). 